\title{
Highly sensitive fluorescence detection of copper ion based on its catalytic oxidation to cysteine indicated by fluorescein isothiocyanate functionalized gold nanoparticles
}

\author{
Shasha Wang ${ }^{\mathrm{a}, \mathrm{c}}$, Xiaokun Wang ${ }^{\mathrm{a}, \mathrm{b}}$, Zhiyang Zhang ${ }^{\mathrm{a}, \mathrm{c}}$, Lingxin Chen ${ }^{\mathrm{a}, *}$ \\ a Key Laboratory of Coastal Environmental Processes and Ecological Remediation, Yantai Institute of Coastal Zone Research, Chinese Academy of Sciences, \\ Yantai 264003, China \\ ${ }^{\mathrm{b}}$ College of Chemistry and Chemical Engineering, Qufu Normal University, Qufu 273165, China \\ ${ }^{c}$ University of Chinese Academy of Sciences, Beijing 100049, China
}

\section{H I G H L I G H T S}

- A fluorescent probe for $\mathrm{Cu}^{2+}$ has been developed by FITC functionalized gold nanoparticles.

- Cysteine could replace FITC from the surfaces of gold nanoparticles and $\mathrm{Cu}^{2+}$ could catalyze $\mathrm{O}_{2}$ oxidation of cysteine.

- The fluorescent probe provides high sensitivity toward $\mathrm{Cu}^{2+}$ in drinking water as a real sample.

\section{A R T I C L E I N F O}

\section{Article history:}

Received 3 September 2014

Received in revised form 2 December 2014

Accepted 22 December 2014

Available online 8 January 2015

\section{Keywords:}

Gold nanoparticles

Fluorescein isothiocyanate

Fluorescence resonance energy transfer

Copper ions

Fluorescence

\section{G R A P H I C A L A B S T R A C T}

A highly sensitive fluorescent sensor for $\mathrm{Cu}^{2+}$ based on its catalytic oxidation of cysteine and cysteineinduced increase in fluorescence intensity of FITC-AuNPs.

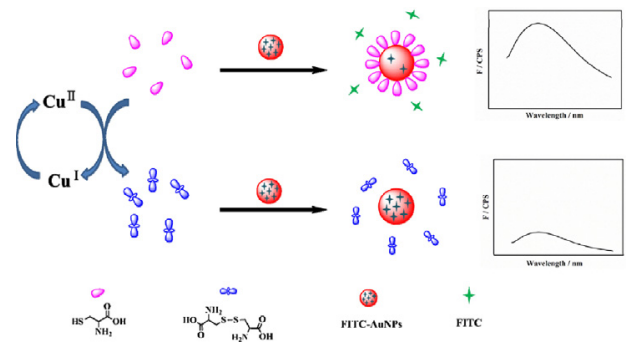

\begin{abstract}
A B S T R A C T
An innovative fluorescence method for sensitive detection of copper ion $\left(\mathrm{Cu}^{2+}\right)$ was developed based on fluorescein isothiocyanate functionalized gold nanoparticles (FITC-AuNPs). Due to the stronger binding affinity of isothiocyanate functional group to gold, FITC molecules could adsorb on the surface of AuNPs, forming a simple fluorescence resonance energy transfer (FRET) system, and the fluorescence intensity of FITC was remarkably quenched. Upon adding cysteine, FITC could be displaced from the surface of AuNPs because the formation constant $\left(K_{\mathrm{f}}\right)$ of Au-S linkage $\left(K_{\mathrm{f}}\left(\mathrm{AuS}^{-}\right)=4 \times 10^{35}\right)$ was much higher than $\mathrm{Au}-\mathrm{SCN}$ linkage $\left(K_{\mathrm{f}}\left(\mathrm{Au}(\mathrm{SCN})^{2-}\right)=10^{23}\right)$, leading to the recovery of fluorescence intensity. However, $\mathrm{Cu}^{2+}$ could catalyze $\mathrm{O}_{2}$ oxidation of cysteine, and the generated disulfide cystine could not remove FITC from AuNPs' surface. Therefore, the recovery of fluorescence intensity was much weaker when compared with that of in the absence of $\mathrm{Cu}^{2+}$. And on the basis of this principle the concentration of $\mathrm{Cu}^{2+}$ could be detected quantitatively. Under optimal conditions, our method exhibited high selectivity toward $\mathrm{Cu}^{2+}$ and provided a good linear relationship in the range of $1.0-17.0 \mathrm{nM}$ with the detection limit of $0.37 \mathrm{nM}$ calculated by $3 \sigma / S$. Furthermore, complicated synthetic procedures and poor water solubility could be ignored in this proposed fluorescent sensor.
\end{abstract}

(c) 2015 Elsevier B.V. All rights reserved.

\footnotetext{
* Corresponding author. Tel.: +86 535 2109130; fax: +86 5352109130.

E-mail address: lxchen@yic.ac.cn (L. Chen).
}

\section{Introduction}

As an indispensable trace element in human body, copper ion $\left(\mathrm{Cu}^{2+}\right)$ plays an important role in the development and function of 
internal organs [1], such as brain, liver and heart. And it also activates the formation of hemoglobin and promotes the absorption and utilization of iron [2]. However, the excessive accumulation of copper is confirmed to be poisonous to humans, in that it can lead to neurodegenerative diseases probably by its involvement in the generation of active oxygen species $[3,4]$. Accordingly, the safe limit of $\mathrm{Cu}^{2+}$ is $1.3 \mathrm{ppm}(\sim 20 \mu \mathrm{M})$ in drinking water recommended by U.S. Environmental Protection Agency (EPA) [5]. The common analytical methods adopted for $\mathrm{Cu}^{2+}$ measurement include atomic emission spectrometry (AES) [6], atomic absorption spectrometry (AAS) [7], inductively coupled plasma mass spectrometry (ICP-MS) [8] and electrochemistry assay [9]. In spite of high selectivity and sensitivity, these methods often require professional operational skills, tedious sample pretreatments and a long analysis time. As a consequence, there has been growing interest in developing new methods for monitoring $\mathrm{Cu}^{2+}$ with high selectivity and sensitivity.

Recently, numerous chemosensors and biosensors have been designed based on nano-materials, e.g. gold nanoparticles (AuNPs) [10-12], gold nanorods (AuNRs) [13-15], carbon dots (CDs) [16-18] and quantum dots (QDs) [19,20]. Among various nano-materials, AuNPs have attracted a great deal of attention for chemical and biological analysis over past decades. Due to their unique optical properties, especially localized surface plasmon resonance (LSPR) [21], AuNPs were widely applied in colorimetric [10,11], fluorescent [22], surface-enhanced Raman scattering [23] and electrochemistry assays [24]. What's more, possessing higher extinction coefficient than those of common organic dyes in the ultraviolet and visible regions [25], AuNPs are emerging as efficient quenchers for fluorophores.

On account of high sensitivity and relative versatility, fluorescent assay has been gained comprehensive attention. However, complicated synthetic procedures and poor water solubility limit the application of most of existing fluorescent methods, which are only based on the design and synthesis of organic compounds. AuNPs have opened up a new alternative for the fabrication of fluorescent chemosensors. Because of AuNPs' high extinction coefficient, fluorophores attached to the surfaces of AuNPs will be quenched by fluorescence resonance energy transfer (FRET) [26]; when added analytes which have much stronger affinity with AuNPs, fluorophore molecules will be replaced, leading to the increase of fluorescence intensity. So far, AuNPs-FRET-based assay has been used to develop sensors for the detection of metal ions [27], inorganic anions [28], small organic molecules [29] and biomolecules [30].

Herein, a simple and sensitive method for fluorescence detection of $\mathrm{Cu}^{2+}$ in aqueous solution at room temperature was proposed based on fluorescein isothiocyanate functionalized gold nanoparticles (FITC-AuNPs). The fluorescence of FITC switched off when attached to the surfaces of AuNPs through forming Au-SCN linkage; upon adding cysteine, FITC was replaced because the Au-S linkage was stronger than Au-SCN linkage, and the fluorescence turned to switch-on. Yet, the oxidation of cysteine by $\mathrm{O}_{2}$ could be catalyzed with the existence of $\mathrm{Cu}^{2+}$, resulting in the formation of disulfide cystine [31,32]. At this point, the recovery of fluorescence was weakened when adding AuNPs. Based on this principle, the quantitative analysis of $\mathrm{Cu}^{2+}$ could be realized and this proposed method also showed high sensitivity toward $\mathrm{Cu}^{2+}$ over other metal ions.

\section{Materials and methods}

\subsection{Chemicals}

Fluorescein isothiocyanate (FITC, 96\%), $\mathrm{Na}_{2} \mathrm{HPO}_{4} \cdot 12 \mathrm{H}_{2} \mathrm{O}$ and $\mathrm{NaH}_{2} \mathrm{PO}_{4} \cdot 2 \mathrm{H}_{2} \mathrm{O}$ were purchased from Aladdin. Hydrogen tetrachloroaurate (III) hydrate $\left(\mathrm{HAuCl}_{4} \cdot 4 \mathrm{H}_{2} \mathrm{O}\right)$, sodium citrate, cysteine, $\mathrm{CuSO}_{4} \cdot 5 \mathrm{H}_{2} \mathrm{O}, \mathrm{MgCl}_{2}, \mathrm{CaCl}_{2}, \mathrm{FeCl}_{3}, \mathrm{NiCl}_{2}, \mathrm{ZnCl}_{2}, \mathrm{Cd}\left(\mathrm{ClO}_{4}\right)_{2}$, $\mathrm{LiCl}, \mathrm{MnCl}_{2}, \mathrm{KCl}, \mathrm{BaCl}_{2}, \mathrm{AgNO}_{3}, \mathrm{~Pb}\left(\mathrm{NO}_{3}\right)_{2}$ and $\mathrm{HgCl}_{2}$ were obtained from Sinopharm Chemical Reagent Company Limited (Beijing, China). All the reagents were of analytical grade and used without any future purification.

\subsection{Apparatus}

Solutions were prepared with double-deionized water (18.2 $\mathrm{M} \Omega \mathrm{cm}$ specific resistance) obtained by a Cascada LS Ultrapure water system (Pall Corp., USA). Transmission electron microscope (TEM) images were captured on a JEM-1230 electron microscope (JEOL Ltd., Japan) operating at $100 \mathrm{kV}$. UV-vis absorption spectra were collected on a Thermo Scientific NanoDrop 2000C spectrophotometer (Gene Company Ltd., USA). The fluorescence spectra were recorded on a Fluoromax-4 spectrofluorometer with a xenon lamp and $0.5 \mathrm{~cm}$ quartz cells (HORIBA Scientific, Japan).

\subsection{Synthesis and modification of AuNPs}

All glasswares used in the following experimental procedure were bathed in freshly prepared $3: 1 \mathrm{HCl}-\mathrm{HNO}_{3}$, rinsed thoroughly with double-deionized water and dried in air. AuNPs were prepared by the citrate-mediated reduction of $\mathrm{HAuCl}_{4}$ according to Frens' method [33]. Typically, $100 \mathrm{~mL}$ of $1.0 \mathrm{mM} \mathrm{HAuCl}_{4}$ was introduced into a three-necked flask and heated to reflux with stirring. Then $10 \mathrm{~mL}$ of $38.8 \mathrm{mM}$ sodium citrate was rapidly added to the boiling solution, resulting in a color change from pale yellow to deep red. The solution was kept boiling for another $30 \mathrm{~min}$, and then cooled to room temperature with continuous stirring. The concentration of the obtained AuNPs solutions was estimated to be $12 \mathrm{nM}$ according to Beer's law $(A=\varepsilon b c)$, where the colorimetric cuvette had a path length $(b)$ of $1 \mathrm{~cm}$ and the extinction coefficient $(\varepsilon)$ of $13 \mathrm{~nm}$ AuNPs at $520 \mathrm{~nm}$ is $2.78 \times 10^{8} \mathrm{M}^{-1} \mathrm{~cm}^{-1}$.

A stock solution of $1.0 \mathrm{mM}$ FITC was prepared in ethanol absolute. Then, $50 \mu \mathrm{L}$ of the prepared FITC solution was added to the $50 \mathrm{~mL}$ AuNPs solution with stirring, and the mixture was equilibrated in the dark at room temperature.

\subsection{Fluorescence detection of $\mathrm{Cu}^{2+}$}

A stock solution of $\mathrm{CuSO}_{4} \cdot 5 \mathrm{H}_{2} \mathrm{O}(0.01 \mathrm{M})$ was prepared in double-deionized water, and different concentrations of $\mathrm{Cu}^{2+}$ solution was acquired by diluting the stock solution accurately. For $\mathrm{Cu}^{2+}$ detection, $10 \mu \mathrm{L}$ various concentrations of $\mathrm{Cu}^{2+}$ solution was added to $890 \mu \mathrm{LNa}_{2} \mathrm{HPO}_{4}-\mathrm{NaH}_{2} \mathrm{PO}_{4}$ buffer $(10 \mathrm{mM})$ at a pH of 6.8 containing $3.0 \mu \mathrm{M}$ cysteine; the mixture solution was incubated at room temperature for $30 \mathrm{~min}$. Then $100 \mu \mathrm{L}$ FITC-AuNPs was added to the mixture solution. $10 \mathrm{~min}$ later, fluorescence spectra were collected at $514 \mathrm{~nm}$ with an excitation wavelength of $490 \mathrm{~nm}$.

To measure the selectivity of the developed method, other metal ions instead of $\mathrm{Cu}^{2+}$ were detected in a similar way under the same optimized conditions.

\subsection{Fluorescence sensing of $\mathrm{Cu}^{2+}$ in drinking water}

The drinking water was obtained locally and 5-fold diluted, then this water sample was used to prepare $10 \mathrm{mM} \mathrm{Na} 2 \mathrm{HPO}_{4}-\mathrm{NaH}_{2} \mathrm{PO}_{4}$ buffer at a pH of 6.8 spiked with standard $\mathrm{Cu}^{2+}$ solutions leading to different final concentrations. $10 \mu \mathrm{L}$ of $300 \mu \mathrm{M}$ cysteine was dissolved in $890 \mu \mathrm{L}$ above buffer solution. After incubation for $30 \mathrm{~min}, 100 \mu \mathrm{L}$ FITC-AuNPs was added to the solution and the mixed solution was equilibrated for another $10 \mathrm{~min}$ before spectra measurement. 
A

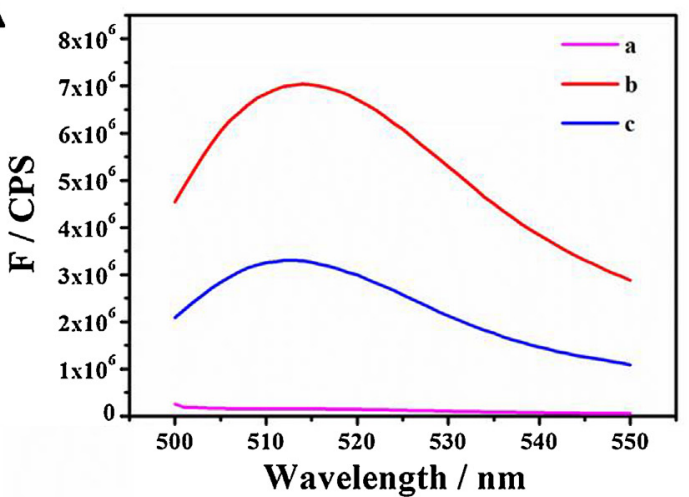

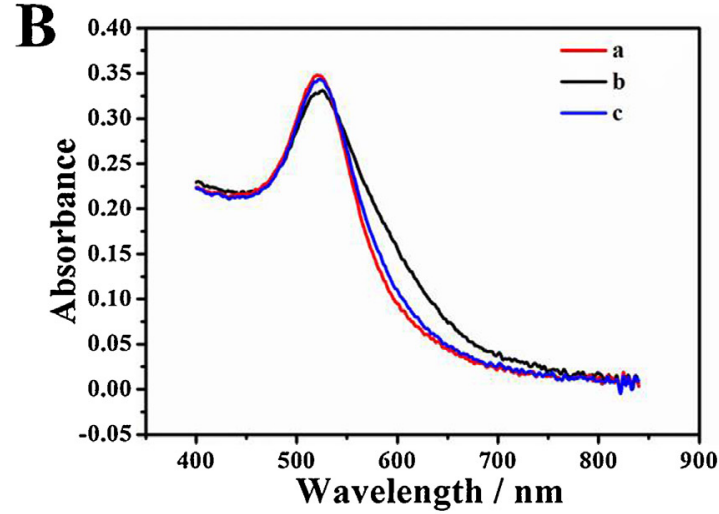

C
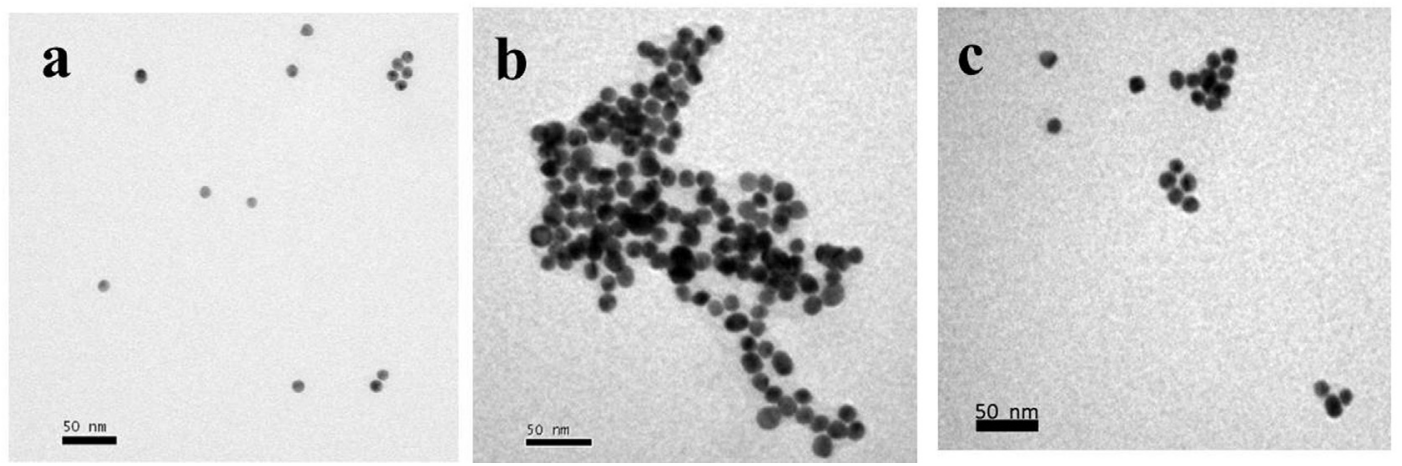

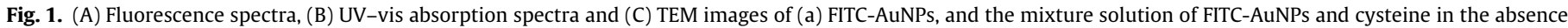
(b) and presence (c) of $20 \mathrm{nM} \mathrm{Cu}^{2+}$. (For interpretation of the references to color in text, the reader is referred to the web version of this article.)

\section{Result and discussion}

\subsection{Characterization of FITC-AuNPS}

FITC-AuNPs were synthesized by adding an optimum concentration of FITC to citrate modified AuNPs. Due to coordinately unsaturated gold atoms at the surface of AuNPs which own unoccupied orbitals available for nucleophiles to donate electrons, the isothiocyanate functional group of the FITC molecule, known as the strong nucleophile, could displace citrate ions from the surface of AuNPs and form stable complexes $\left(K_{\mathrm{f}}\left(\mathrm{Au}(\mathrm{SCN})_{2}{ }^{-}\right)=10^{23}\right)$ with gold (I) [34]. The UV-vis absorption spectrum of FITC-AuNPs exhibited an intense characteristic LSPR peak at $\sim 520 \mathrm{~nm}$ (Fig. 1B, curve a), and the color of the as-synthesizd FITC-AuNPs suspension was remained wine red, indicating a good mono-dispersion of FITC-AuNPs in water. TEM image (Fig. 1C, image a) proved that the average particle size of FITC capped AuNPs was $13 \mathrm{~nm}$.

In order to further demonstrate that FITC was modified on the surface of AuNPs, $100 \mu \mathrm{L}$ FITC-AuNPs was diluted to $1.0 \mathrm{~mL}$ by $10 \mathrm{mM} \mathrm{Na} \mathrm{HPO}_{4}-\mathrm{NaH}_{2} \mathrm{PO}_{4}$ buffer at a $\mathrm{pH}$ of 6.8 . At this time the concentration of FITC was equal to $0.1 \mu \mathrm{M}$. For purpose of remove AuNPs, the mixture solution was separated by centrifugation and the fluorescence intensity of obtained supernatant was recorded. Compared with that of $0.1 \mu \mathrm{M}$ FITC prepared by $10 \mathrm{mM}$ $\mathrm{Na}_{2} \mathrm{HPO}_{4}-\mathrm{NaH}_{2} \mathrm{PO}_{4}$ buffer (Fig. S1, black line), the fluorescence intensity of supernatant (Fig. S1, red line) was much lower, meaning the successful modification of FITC to AuNPs.

Moreover, the concentration of FITC was of great importance to carry out this sensing study. The optimal concentration of FITC should satisfy that not only enough FITC was required to saturate the surface of AuNPs, but also no free FITC was dispersed in the solution. In this work, the concentration of FITC was investigated by adding various amounts of FITC to $5 \mathrm{~mL}$ AuNPs. As shown in Fig. S2, the fluorescence intensity enhanced extraordinarily upon increasing concentration of FITC up to $\sim 1.0 \mu \mathrm{M}$, which could be attributed to the presence of free FITC molecules. Additionally, the fluorescence intensity was dramatically quenched at concentrations below $1.0 \mu \mathrm{M}$, indicating almost all the FITC molecules were adsorbed on AuNPs surface. Thus, the concentration of $1.0 \mu \mathrm{M}$ was chosen as the optimum concentration of FITC to conduct the following experiments.

\subsection{Sensing mechanism}

Scheme 1 illustrates the sensing mechanism for fluorescence detection of $\mathrm{Cu}^{2+}$. By virtue of AuNPs' high extinction coefficient, when FITC was capped on the surface of AuNPs, a simple FRET system was composed in which AuNPs and FITC act as the acceptor and donor, respectively. As a consequence, the fluorescence intensity of FITC was remarkably quenched (Fig. 1A, curve a). Upon addition of sulfydryl-containing cysteine, which has higher binding affinity of Au-S linkage $\left(K_{\mathrm{f}}\left(\mathrm{AuS}^{-}\right)=4 \times 10^{35}\right)$ than that of Au-SCN linkage $\left(K_{\mathrm{f}}\left(\mathrm{Au}(\mathrm{SCN})_{2}{ }^{-}\right)=10^{23}\right)$ [35], FITC molecules were effectively replaced and released to reaction solution, leading to the recovery of fluorescence intensity (Fig. 1A, curve b). However, the presence of $\mathrm{Cu}^{2+}$ could catalyze the oxidation of cysteine by $\mathrm{O}_{2}$, resulting in the formation of disulfide cystine. The detailed catalytic reaction equations [31] were shown in Eq. (S1). With the addition of FITC-AuNPs, the generated disulfide cystine could not displace FITC molecules from the AuNPs' surface, leading to the weak recovery of fluorescence intensity (Fig. 1A, curve c).

To further demonstrate the proposed sensing mechanism, UV-vis absorption spectra and TEM images were also displayed. As indicated in Fig. 1B (curve a), the addition of cysteine induced the aggregation of FITC-AuNPs, leading to the decline of LSPR peak at $520 \mathrm{~nm}$ along with the emergence of a long wavelength band. This result was because that cysteine could be attached to the surface of AuNPs through formating $\mathrm{Au}-\mathrm{S}$ bonds, and aggregation of 


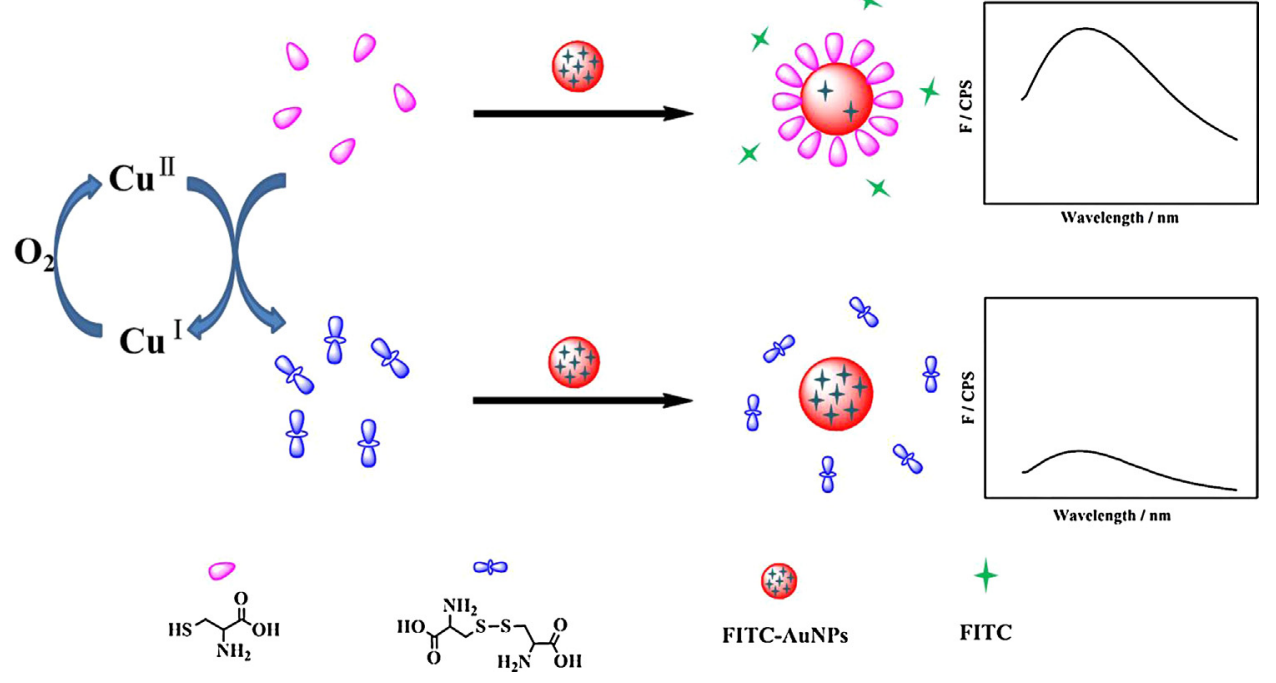

Scheme 1. Schematic illustration of fluorescent sensing $\mathrm{Cu}^{2+}$ based on its catalysis to cysteine by FITC-AuNPs.

AuNPs occurred by electrostatic interaction among cysteine capped AuNPs. However, the presence of $\mathrm{Cu}^{2+}$ could catalyze the oxidation of cysteine by $\mathrm{O}_{2}$, and the aggregation of FITC-AuNPs was inhibited (Fig. 1B, curve c). These results were confirmed by TEM images, revealing aggregated FITC-AuNPs in the presence of cysteine (Fig. 1C, image b), and slightly aggregated FITC-AuNPs when cysteine was first treated with $\mathrm{Cu}^{2+}$ (Fig. 1C, image c).

Furthermore, the role of dissolved oxygen to the oxidation of cysteine has also been discussed. As shown in Fig. S3, when bubbling $\mathrm{N}_{2}$ to remove dissolved oxygen during the reaction, the fluorescence intensity (black line) was stronger in contrast to that unbubbling $\mathrm{N}_{2}$ (red line). The results indicated that the oxidation of cysteine needs the participation of oxygen. The dissolved oxygen at $25^{\circ} \mathrm{C}$ was $8.25 \mathrm{mg} / \mathrm{mL}(\sim 258 \mu \mathrm{M})$, which could meet the needs of catalytic oxidation reaction.

\subsection{Optimization of experimental conditions}

The sensitivity of this proposed method was closely related to experimental parameters including $\mathrm{pH}$, concentration of cysteine, the catalytic reaction time and the responsive time. The value of $F-F_{\text {blank }}$ was explored to evaluate experiments, where $F$ and $F_{\text {blank }}$ indicated the fluorescence intensities at $514 \mathrm{~nm}$ of reaction solution with or without $\mathrm{Cu}^{2+}$, respectively.

To investigate the effect of $\mathrm{pH}$ to the value of $F-F_{\text {blank }}$, the experiment was performed in the $\mathrm{pH}$ ranging from 6.0 to 8.0 obtained by adjusting the ratio of $\mathrm{NaH}_{2} \mathrm{PO}_{4}$ to $\mathrm{Na}_{2} \mathrm{HPO}_{4}$. As seen in Fig. S4A, the value of $F-F_{\text {blank }}$ was found to be $\mathrm{pH}$-dependent. On one hand, the fluorescence intensity of FITC increased with increasing concentration of hydroxide ion because the $\mathrm{p} K_{\mathrm{a}}$ for FITC was 6.4 [22]. On the other hand, hydrogen ion could be propitious to catalytic reaction because it would involve the reaction of $\mathrm{O}_{2}{ }^{--}$and $\mathrm{RS}^{-} \mathrm{Cu}^{\mathrm{I}}$. Considering the above two factors, an optimum $\mathrm{pH}$ at 6.8 was chosen for $\mathrm{Cu}^{2+}$ in the following experiments.

The concentration of cysteine played an important role in this sensing strategy, therefore, it was necessary to evaluate the effect of the concentration of cysteine. Fig. S4B showed the value of $F-F_{\text {blank }}$ in different concentrations of cysteine. It was noted that the value of $F-F_{\text {blank }}$ gradually increased in the range from $1.0 \mu \mathrm{M}$ to $3.0 \mu \mathrm{M}$; when the concentration was higher than $3.0 \mu \mathrm{M}$, the value exhibited a downward trend. Meanwhile, the concentration of FITC in the sensing system was $0.1 \mu \mathrm{M}$, which means higher than $0.1 \mu \mathrm{M}$ of the given cysteine was required theoretically in order to completely displace the FITC molecules from the AuNPs surface. As the results indicated, we chose $3.0 \mu \mathrm{M}$ of cysteine to carry out the experiments, and the quantitation for $\mathrm{Cu}^{2+}$ was rationally feasible.

Effects of the catalytic reaction time and the responsive time were also considered for improving the sensitivity toward $\mathrm{Cu}^{2+}$. As illustrated in Fig. S4C, the value of $F-F_{\text {blank }}$ gradually increased with the catalytic reaction time before $30 \mathrm{~min}$ and then varied slightly. And for the responsive time, it can be deduced that the FITC displacement with cysteine was completed within $10 \mathrm{~min}$ (Fig. S4D). Hence, all the following tests were carried out with a catalytic reaction time of $30 \mathrm{~min}$ and a responsive time of $10 \mathrm{~min}$, respectively.

\subsection{Selectivity and sensitivity for $\mathrm{Cu}^{2+}$}

In order to investigate the selectivity of this proposed method toward $\mathrm{Cu}^{2+}$, other metal ions, including $10.0 \mu \mathrm{M} \mathrm{Li}^{+}, \mathrm{K}^{+}, \mathrm{Ca}^{2+}, \mathrm{Mg}^{2+}$, $\mathrm{Ba}^{2+}, \mathrm{Zn}^{2+}, \mathrm{Fe}^{3+}, \mathrm{Cd}^{2+}, \mathrm{Mn}^{2+}, 1.0 \mu \mathrm{M} \mathrm{Pb}^{2+}, \mathrm{Ni}^{2+}$ and $100 \mathrm{nM} \mathrm{\textrm {Ag } ^ { + }}$, $\mathrm{Hg}^{2+}$ were examined under optimum conditions. As illustrated in Fig. 2, only $\mathrm{Cu}^{2+}$ had a distinct fluorescence quenching by comparison with that of blank and the presence of other metal ions. These results clearly showed our approach could selectively detect $\mathrm{Cu}^{2+}$ over other metal ions.

We further explored the analytical performance of this assay for the determination of $\mathrm{Cu}^{2+}$. Under optimized detection conditions, the fluorescence spectra of reaction solution with different

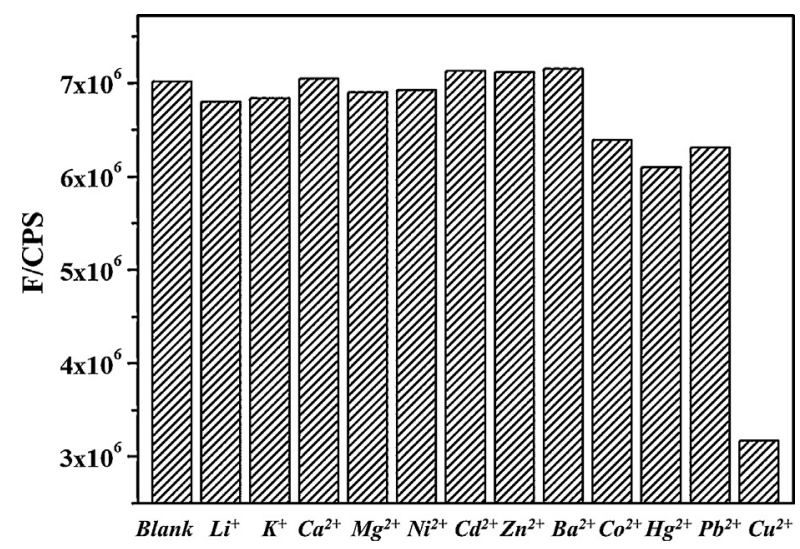

Fig. 2. The value of $F$ in the presence of $20.0 \mathrm{nM} \mathrm{Cu}^{2+}$ or $10.0 \mu \mathrm{M} \mathrm{Li}^{+}, \mathrm{K}^{+}, \mathrm{Ca}^{2+}, \mathrm{Mg}^{2+}$, $\mathrm{Ba}^{2+}, \mathrm{Zn}^{2+}, \mathrm{Fe}^{3+}, \mathrm{Cd}^{2+}, \mathrm{Mn}^{2+}, 1.0 \mu \mathrm{M} \mathrm{Pb}^{2+}, \mathrm{Ni}^{2+}, 100 \mathrm{nM} \mathrm{Ag}^{+}, \mathrm{Hg}^{2+}$, where $F$ indicated the fluorescence intensities at $514 \mathrm{~nm}$. 


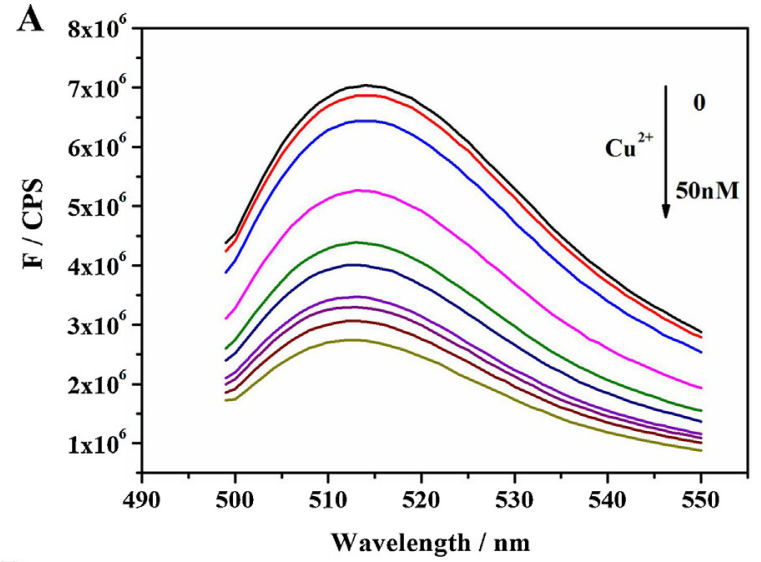

B

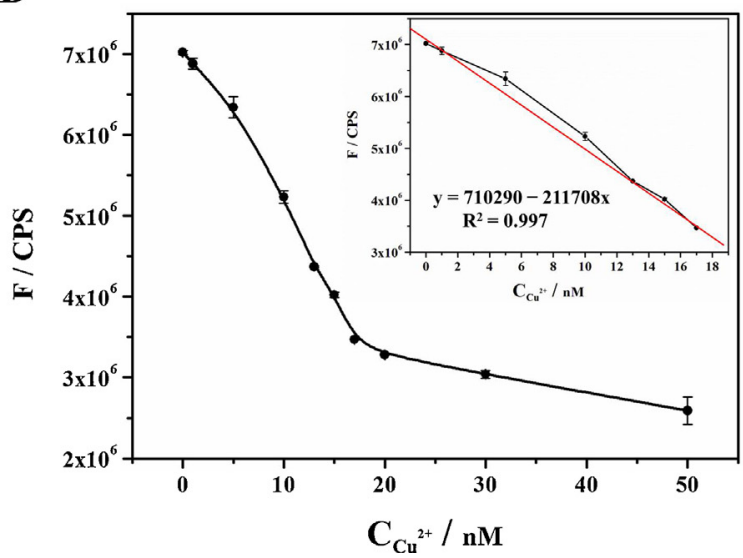

Fig. 3. (A) Fluorescence spectra of reaction solution upon the addition of $\mathrm{Cu}^{2+}$ with different concentrations. (B) A plot of $F-F_{\text {blank }}$ versus different concentrations of $\mathrm{Cu}^{2+}$. Inset shows a linear relationship in the range of $1.0-17.0 \mathrm{nM}$. The error bars represent standard deviations obtained from three parallel experiments.

concentrations of $\mathrm{Cu}^{2+}$ were recorded. As shown in Fig. 3A, with the increasing concentrations of $\mathrm{Cu}^{2+}$, there was a gradual decrease in the fluorescence intensity at $514 \mathrm{~nm}$. For the sake of quantitative analysis of $\mathrm{Cu}^{2+}$, the value of fluorescence intensity at $514 \mathrm{~nm}$ was utilized. A good linear relationship was found in the range from $1.0 \mathrm{nM}$ to $17.0 \mathrm{nM}$, and the detection limit was $0.37 \mathrm{nM}$ calculated by $3 \sigma / S$ (Fig. 3B). Therefore, our developed approach was demonstrated sensitively for the detection of $\mathrm{Cu}^{2+}$. The comparison of

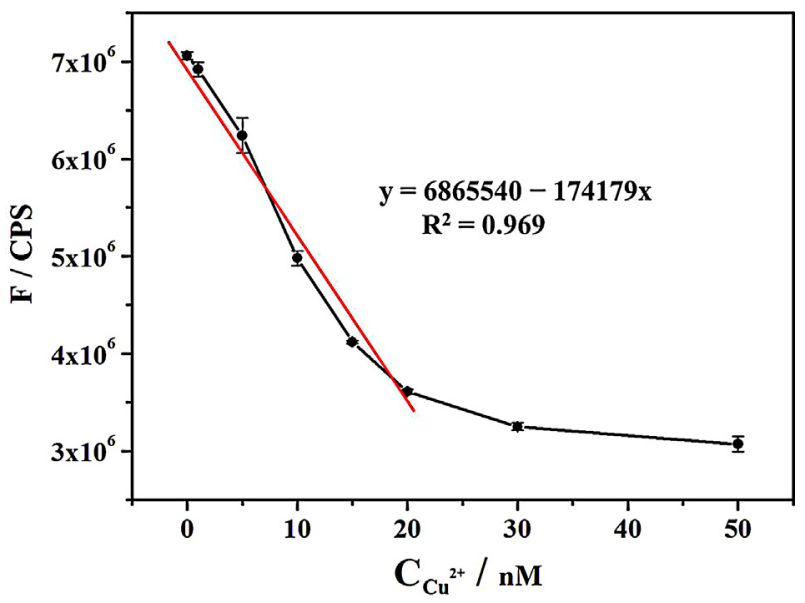

Fig. 4. A plot of $F-F_{\text {blank }}$ versus different concentrations of $\mathrm{Cu}^{2+}$ in drinking water samples. The error bars represent standard deviations obtained from three parallel experiments. analytical performances between our developed method and some reported colorimetric and fluorescent methods for $\mathrm{Cu}^{2+}$ detection was shown in Table S1.

\subsection{Detection of $\mathrm{Cu}^{2+}$ in real samples}

To evaluate the practical utilization of the developed fluorescence detection of $\mathrm{Cu}^{2+}$ in real samples, barreled mineral water was spiked with $\mathrm{Cu}^{2+}$ and measured in the assay. As shown in Fig. 4, the values of fluorescence intensity were found to be dependent on the concentration of $\mathrm{Cu}^{2+}$. A linear decrease of fluorescence intensity versus the concentration of $\mathrm{Cu}^{2+}$ over the range from $1.0 \mathrm{nM}$ to $20.0 \mathrm{nM}$ was observed with the detection limit of $0.64 \mathrm{nM}$ based on $3 \sigma / S$. Hence, these results suggested that this proposed method was suitable for determination of $\mathrm{Cu}^{2+}$ in real samples.

\section{Conclusion}

In summary, we reported a highly sensitive fluorescent sensor for the detection of $\mathrm{Cu}^{2+}$ based on the catalytic oxidation of cysteine by $\mathrm{Cu}^{2+}$ and cysteine-induced increase in fluorescence intensity of FITC-AuNPs. This assay exhibited excellent selectivity toward $\mathrm{Cu}^{2+}$ over other mental ions. And our sensing system successfully avoided complicated synthetic procedures and poor water solubility relative to other fluorescent methods. What's more, the experimental results provided a great potential application of the proposed method in real samples, thus paving the way for wide use of AuNPs in design of optical sensors.

\section{Acknowledgements}

This work was financially supported by the National Natural Science Foundation of China (grant no. 21275158), and the 100 Talents Program of the Chinese Academy of Sciences.

\section{Appendix A. Supplementary data}

Supplementary data associated with this article can be found, in the online version, at http://dx.doi.org/10.1016/j.colsurfa. 2014.12.050.

\section{References}

[1] J.R. Prohaska, Functions of trace elements in brain metabolism, Physiol. Rev. 67 (1987) 858-901

[2] E.D. Harris, Y. Qian, E. Tiffany-Castiglioni, A.R. Lacy, M.C. Reddy, Functional analysis of copper homeostasis in cell culture models: a new perspective on internal copper transport, Am. J. Clin. Nutr. 67 (1998) 988S-995S.

[3] R.A. Lovstad, A kinetic study on the distribution of Cu (II)-ions between albumin and transferrin, BioMetals 17 (2004) 111-113.

[4] K.J. Barnham, C.L. Masters, A.I. Bush, Neurodegenerative diseases and oxidative stress, Nat. Rev. Drug Discov. 3 (2004) 205-214.

[5] Y.T. Su, G.Y. Lan, W.Y. Chen, H.T. Chang, Detection of copper ions through recovery of the fluorescence of DNA-templated copper/silver nanoclusters in the presence of mercaptopropionic acid, Anal. Chem. 82 (2010) 8566-8572.

[6] T.R. Harville, R.K. Marcus, Line selection and evaluation of radio frequency glow discharge atomic emission spectrometry for the analysis of copper and aluminum alloys, Anal. Chem. 65 (1993) 3636-3643.

[7] C.A. Sahin, I. Tokgoz, S. Bektas, Preconcentration and determination of iron and copper in spice samples by cloud point extraction and flow injection flame atomic absorption spectrometry, J. Hazard. Mater. 181 (2010) 359-365.

[8] J. Djedjibegovic, T. Larssen, A. Skrbo, A. Marjanovic, M. Sober, Contents of cadmium, copper, mercury and lead in fish from the Neretva river (Bosnia and Herzegovina) determined by inductively coupled plasma mass spectrometry (ICP-MS), Food Chem. 131 (2012) 469-476.

[9] M.N. Kopylovich, K.T. Mahmudov, A.J.L. Pombeiro, Poly (vinyl) chloride membrane copper-selective electrode based on 1-phenyl-2-(2hydroxyphenylhydrazo)-butane-1,3-dione, J. Hazard. Mater. 186 (2011) $1154-1162$.

[10] J. Zhou, X.H. Xu, X. Liu, H. Li, Z. Nie, M. Qing, Y. Huang, S.Z. Yao, A gold nanoparticles colorimetric assay for label-free detection of protein kinase activity based 
on phosphorylation protection against exopeptidase cleavage, Biosens. Bioelectron. 53 (2014) 295-300.

[11] C.Y. Lin, C.J. Yu, Y.H. Lin, W.L. Tseng, Colorimetric sensing of silver (I) and mercury (II) ions based on an assembly of Tween 20-stabilized gold nanoparticles, Anal. Chem. 82 (2010) 6830-6837.

[12] R.L. Liu, Z.P. Chen, S.S. Wang, C.L. Qu, L.X. Chen, Z. Wang, Colorimetric sensing of copper (II) based on catalytic etching of gold nanoparticles, Talanta 112 (2013) 37-42.

[13] X.L. Fu, L.X. Chen, J.H. Li, M. Lin, H.Y. You, W.H. Wang, Label-free colorimetric sensor for ultrasensitive detection of heparin based on color quenching of gold nanorods by graphene oxide, Biosens. Bioelectron. 34 (2012) 227-231.

[14] S.S. Wang, Z.P. Chen, L. Chen, R.L. Liu, L.X. Chen, Label-free colorimetric sensing of copper(II) ions based on accelerating decomposition of $\mathrm{H}_{2} \mathrm{O}_{2}$ using gold nanorods as an indicator, Analyst 138 (2013) 2080-2084.

[15] J. Wang, P. Zhang, C.M. Lia, Y.F. Li, C.Z. Huang, A highly selective and colorimetric assay of lysine by molecular-driven gold nanorods assembly, Biosens. Bioelectron. 34 (2012) 197-201.

[16] W. Wang, Y.M. Li, L. Cheng, Z.Q. Cao, W.G. Liu, Water-soluble and phosphoruscontaining carbon dots with strong green fluorescence for cell labeling, J. Mater. Chem. B 2 (2014) 46-48.

[17] S. Maiti, K. Dasa, P.K. Das, Label-free fluorimetric detection of histone using quaternized carbon dot-DNA nanobiohybrid, Chem. Commun. 49 (2013) 8851-8853.

[18] R.X. Wang, G.L. Li, Y.Q. Dong, Y.W. Chi, G.N. Chen, Carbon quantum dotfunctionalized aerogels for $\mathrm{NO}_{2}$ gas sensing Anal Chem. 85 (2013) 8065-8069.

[19] P.P. Yan, Q.H. Tang, A.P. Deng, J.G. Li, Ultrasensitive detection of clenbuterol by quantum dots based electrochemiluminescent immunosensor using gold nanoparticles as substrate and electron transport accelerator, Sens. Actuator B: Chem. 191 (2014) 508-515.

[20] C. Yuan, K. Zhang, Z.P. Zhang, S.H. Wang, Highly selective and sensitive detection of mercuric ion based on a visual fluorescence method, Anal. Chem. 84 (2012) 9792-9801.

[21] K.M. Mayer, J.H. Hafner, Localized surface plasmon resonance sensors, Chem. Rev. 111 (2011) 3828-3857.

[22] M.R. Hormozi-Nezhad, H. Bagheri, A. Bohloul, N. Taheri, H. Robatjazi, Highly sensitive turn-on fluorescent detection of captopril based on energy transfer between fluorescein isothiocyanate and gold nanoparticles, J. Lumin. 134 (2013) 874-879.
[23] S. Jung, J. Nam, S. Hwang, J. Park, J. Hur, K. Im, N. Park, S. Kim, Theragnostic pH-sensitive gold nanoparticles for the selective surface enhanced Raman scattering and photothermal cancer therapy, Anal. Chem. 85 (2013)7674-7681.

[24] L. Lin, Y. Liu, L.L. Tang. J.H. Li, Electrochemical DNA sensor by the assembly of graphene and DNA-conjugated gold nanoparticles with silver enhancement strategy, Analyst 136 (2011) 4732-4737.

[25] X.Y. Xu, W.L. Daniel, W. Wei, C.A. Mirkin, Colorimetric $\mathrm{Cu}^{2+}$ detection using DNA-modified gold-nanoparticle aggregates as probes and click chemistry, Small 6 (2010) 623-626.

[26] H. Lee, K. Lee, I.K. Kim, T.G. Park, Fluorescent gold nanoprobe sensitive to intracellular reactive oxygen species, Adv. Funct. Mater. 19 (2009) 1884-1890.

[27] X. Wang, X.Q. Guo, Ultrasensitive $\mathrm{Pb}^{2+}$ detection based on fluorescence resonance energy transfer (FRET) between quantum dots and gold nanoparticles, Analyst 134 (2009) 1348-1354

[28] M. Xue, X. Wang, H. Wang, D.Z. Chen, B. Tang, Hydrogen bond breakage by fluoride anions in a simple CdTe quantum dot/gold nanoparticle FRET system and its analytical application, Chem. Commun. 47 (2011) 4986-4988.

[29] H.H. Cai, H. Wang, J.H. Wang, W. Wei, P.H. Yang. J.Y. Cai, Naked eye detection of glutathione in living cells using rhodamine B-functionalized gold nanoparticles coupled with FRET, Dyes Pigment. 92 (2012) 778-782.

[30] C.Y. Lin, C.H. Liu, W.L. Tseng, Fluorescein isothiocyanate-capped gold nanoparticles for fluorescent detection of reactive oxygen species based on thio oxidation and their application for sensing glucose in serum, Anal. Methods 2 (2010) 1810-1815.

[31] L. Pecci, G. Montefoschi, G. Musci, D. Cavallini, Novel findings on the copper catalysed oxidation of cysteine, Amino Acids 13 (1997) 355-367.

[32] C.H. Lu, Y.W. Wang, S.L. Ye, G.N. Chen, H.H. Yang, Ultrasensitive detection of $\mathrm{Cu}^{2+}$ with the naked eye and application in immunoassays, NPG Asia Mater. (2012), http://dx.doi.org/10.1038/am.2012.18.

[33] G. Frens, Controlled nucleation for the regulation of the particle size in monodisperse gold suspensions, Nat. Phys. Sci. 241 (1973) 20-24

[34] L.M. Ao, F. Gao, B.F. Pan, R. He, D.X. Cui, Fluoroimmunoassay for antigen based on fluorescence quenching signal of gold nanoparticles, Anal. Chem. 78 (2006) 1104-1106.

[35] S.C.Wei, P.H.Hsu, Y.F. Lee, Y.W. Lin, C.C. Huang, Selective detection of iodide and cyanide anions using gold-nanoparticle-based fluorescent probes, ACS Appl. Mater. Interfaces 4 (2012) 2652-2658. 